\title{
The Performance of Different Mapping Functions and Gradient Models in the Determination of Slant Tropospheric Delay
}

\author{
Cong Qiu ${ }^{1,2}$, Xiaoming Wang ${ }^{1, *}$, Zishen $\mathrm{Li}^{1}{ }^{1}$, Shaotian Zhang ${ }^{1,2}$, Haobo Li ${ }^{3}$, Jinglei Zhang ${ }^{4}$ \\ and Hong Yuan ${ }^{1}$ \\ 1 Aerospace Information Research Institute, Chinese Academy of Sciences, No.9 Dengzhuang South Road, \\ Haidian District, Beijing 100094, China; qiucong@aircas.ac.cn (C.Q.); lizishen@aoe.ac.cn (Z.L.); \\ zhangshaotian18@mails.ucas.ac.cn (S.Z.); yuanhong@aircas.ac.cn (H.Y.) \\ 2 School of Electronic, Electrical and Communicating Engineering, University of Chinese Academy of Sciences, \\ No.19A Yuquan Road, Shijingshan District, Beijing 100049, China \\ 3 School of Environment Science and Spatial Informatics, China University of Mining and \\ Technology (Xuzhou), No.1 Daxue Road, Xuzhou 221116, China; tb17160006b1@cumt.edu.cn \\ 4 School of Land Science and Technology, China University of Geosciences (Beijing), 29 Xue Yuan Road, \\ Haidian District, Beijing 100083, China; 2112180016@cugb.edu.cn \\ * Correspondence: wxm@aoe.ac.cn; Tel.: +86-10-82178896
}

Received: 28 October 2019; Accepted: 23 December 2019; Published: 1 January 2020

\begin{abstract}
Global navigation satellite systems (GNSSs) have become an important tool for remotely sensing water vapor in the atmosphere. In GNSS data processing, mapping functions and gradient models are needed to map the zenith tropospheric delay (ZTD) to the slant total tropospheric delay (STD) along a signal path. Therefore, it is essential to investigate the spatial-temporal performance of various mapping functions and gradient models in the determination of STD. In this study, the STDs at nine elevations were first calculated by applying the ray-tracing method to the atmospheric European Reanalysis-Interim (ERA-Interim) dataset. These STDs were then used as the reference to study the accuracy of the STDs that determined the ZTD together with mapping functions and gradient models. The performance of three mapping functions (i.e., Niell mapping function (NMF), global mapping function (GMF), and Vienna mapping function (VMF1)) and three gradient models (i.e., Chen, MacMillan, and Meindl) in six regions (the temperate zone, Qinghai-Tibet Plateau, Equator, Sahara Desert, Amazon Rainforest, and North Pole) in determining slant tropospheric delay was investigated in this study. The results indicate that the three mapping functions have relatively similar performance above a $15^{\circ}$ elevation, but below a $15^{\circ}$ elevation, VMF1 clearly performed better than the GMF and NMF. The results also show that, if no gradient model is included, the root-mean-square (RMS) of the STD is smaller than $2 \mathrm{~mm}$ above the $30^{\circ}$ elevation and smaller than $9 \mathrm{~mm}$ above the $15^{\circ}$ elevation but shows a significant increase below the $15^{\circ}$ elevation. For example, in the temperate zone, the RMS increases from approximately $35 \mathrm{~mm}$ at the $10^{\circ}$ elevation to approximately $160 \mathrm{~mm}$ at the $3^{\circ}$ elevation. The inclusion of gradient models can significantly improve the accuracy of STDs by $50 \%$. All three gradient models performed similarly at all elevations and in all regions. The bending effect was also investigated, and the results indicate that the tropospheric delay caused by the bending effect is normally below $13 \mathrm{~mm}$ above a $15^{\circ}$ elevation, but this delay increases dramatically from approximately $40 \mathrm{~mm}$ at a $10^{\circ}$ elevation to approximately $200 \mathrm{~mm}$ at a $5^{\circ}$ elevation, and even reaches $500-700 \mathrm{~mm}$ at a $3^{\circ}$ elevation in most studied regions.
\end{abstract}

Keywords: tropospheric delay; mapping function; gradient models; bending effect 


\section{Introduction}

Global navigation satellite systems (GNSSs) have become an important tool for remotely sensing water vapor in the atmosphere. The atmospheric information obtained from GNSS has provided a valuable complementary data source, not only for weather forecasting, but also for climate studies. The concept of global positioning system (GPS) meteorology was proposed by Bevis, et al. [1] to retrieve zenith wet delay (ZWD) and precipitable water vapor (PWV). ZWD represents the propagation delay in the zenith direction caused by the water vapor to the GNSS signal, while PWV is the depth of liquid water per unit area after precipitating all the water vapor over a given location at the zenith. PWV derived from GNSS has been proven to be accurate and reliable by comparing it to the value derived from water vapor radiometry (WVR) measurements [2], which is tuned to measure the microwave emissions of the vapor and liquid water molecules in the atmosphere at specific frequencies, with a root-mean-square (RMS) error of 1-2 mm [3,4]. Previous studies have shown that the GNSS-derived ZTD (the propagation delay of GNSS signal owing to the total effect of water vapor and dry air at the zenith), ZWD, and PWV [5,6] have a very high accuracy [7-11], as well as and the ability to capture the evolution of severe weather [12-14] and climate change [4,12,15-18], or can be used in operational weather forecasting by assimilating these variables into a numerical weather prediction (NWP) model $[19,20]$. However, ZWD and PWV are integrated values over a GNSS station and do not provide any information on the vertical distribution of water vapor, which means that severe weather evolution is not always captured by only monitoring ZWD or PWV [21].

Slant wet delay (SWD) or slant water vapor (SWV), which is the wet delay or the total precipitable water vapor in the slant direction, has the ability to capture the water vapor variation in both the horizontal and vertical directions and contains more information than that of the ZWD or PWV [21,22]. Ha, et al. [23] assimilated simulative GPS-derived SWD data, which excelled in the reconstruction of water vapor information in a hypothetical network of ground-based GNSS receivers and short-term rainfall prediction. Seko, et al. [24] compared water vapor's vertical distribution from radial wind (RW) stemming from Doppler radar and SWV calculated by GPS, with RW stemming from Doppler radar and PWV calculated by GPS; the former improved the presentation of the vertical water vapor distribution. Bauer, et al. [25] demonstrated the remarkable improvement of nowcasting and short-range weather forecasting when assimilating GPS-derived slant total delays (STDs) into the numerical weather prediction model (NWM). Kawabata, et al. [26] indicated that assimilating STDs, rather than ZTDs or PWV, improves the recovery of the moisture and temperature fields and increases the accuracy of local heavy rainfall NWP forecasting.

Apart from assimilating STD, SWD, or SWV into NWP models, we can also reconstruct the 3D water variation with SWV using the tomography technique [27-30]. Flores, et al. [31] showed that the tomographic technique is a powerful tool for retrieving the 3D variation in tropospheric refractivity with the GPS observations from a regional dense network. Subsequently, numerous studies have been conducted to improve the performance of the tomographic technique in retrieving 3D water vapor fields [32-38].

The accuracy of the assimilated SWV determines the weather prediction performance and 3D tomography. Bender, et al. [39] also indicated that it is very important in GNSS tomography to use high-accuracy STDs with low elevations to reconstruct the boundary layer. In GNSS data processing, the STD cannot be directly estimated because too many unknowns would be involved. Usually, high-accuracy ZTDs can be derived with the double difference (DD) method, where some common error sources are removed. Additionally, ZTDs can be estimated with precise point positioning (PPP) [9,40-47].

In GNSS data processing, it is almost impossible to determine the tropospheric delay directly, because this will introduce too many unknowns into the equations. To reduce the unknowns of the tropospheric delay to be estimated, instead of estimating STD directly, the STD is usually represented as a function of ZTD (a piece-wise linear value), mapping functions, and gradient models. ZTD consists of zenith hydrostatic delay (ZHD) and ZWD, and the mapping function is divided into two 
components, hydrostatic and wet mapping functions [48]. Considering the effect of the asymmetry of the atmosphere on the ZTD estimation, various types of gradient models [49-51] have been introduced into GNSS data processing to further improve the accuracy of the STD. Therefore, slant hydrostatic delay (SHD) or SWD can be expressed as a function of ZHD or ZWD, respectively:

$$
\begin{gathered}
\mathrm{SHD}=\mathrm{ZHD} \times m_{h}(\varepsilon)+G_{h}\left(G_{N h}, G_{E h}, \varepsilon, \alpha\right)+R_{h}, \\
\mathrm{SWD}=\mathrm{ZWD} \times m_{w}(\varepsilon)+G_{w}\left(G_{N w}, G_{E w}, \varepsilon, \alpha\right)+R_{w},
\end{gathered}
$$

where $\alpha$ and $\varepsilon$ are the azimuth and elevation, respectively; $m_{h}$ and $m_{w}$ are the hydrostatic and wet mapping functions, respectively; $G_{h}$ and $G_{w}$ represent the hydrostatic and wet gradient models, respectively; and $G_{N i}$ and $G_{E i}(i=h, w)$ are the north-south and east-west gradient parameters, designated by indices of " $h$ " (hydrostatic) or " $w$ " (wet), respectively.

ZHD is acquired with a model for the surface pressure [52,53], and ZWD can be obtained through ZTD minus ZHD. In recent decades, based on the isotropy of the atmosphere, a mapping function has been developed that avoids directly ranking defects resulting from estimating STD with an arbitrary azimuthal angle and elevation angle [54]. The most commonly used mapping functions include CfA-2.2 [48], Ifadis [55], mapping temperature test (MTT) [56], NMF [57], GMF [58], and VMF1 [59], which were developed using either radiosonde observations or atmospheric reanalysis data.

To account for the effect of atmospheric anisotropy, many gradient models have been proposed for Very Long Baseline Interferometry (VLBI) and GNSS data processing. There have been few studies on the effect of gradient models during the past few decades. Furthermore, although hydrostatic and wet gradients are estimated separately in Equations (1) and (2), the total gradient, rather than the separate gradients, is currently used in postprocessing [60]. Therefore, three total gradient models are most commonly used today. These gradient models are applied in the GNSS post-processing software GAMIT [50], GIPSY [61], and Bernese [51].

As mentioned above, STDs derived from GNSS, especially those at low elevations, are very useful in retrieving 3D water vapor distributions or in weather forecasting by assimilating them into an NWP model. Therefore, it is important to investigate the accuracy of commonly used mapping functions and gradient models and their impact on the determination of STD. In this study, the performance of three mapping functions-NMF [57], GMF [58], and VMF1 [59]—and three gradient models—Macmillan [49], Chen and Herring [50], and Meindl, Schaer, Hugentobler and Beutler [51]—were studied using the atmospheric reanalysis dataset ERA-Interim provided by the European Centre For Medium-Range Weather Forecasts (ECMWF) [62]. A ray-tracing technique [63] was used to determine the STD, SHD, and SWD at nine elevations (i.e., $70^{\circ}, 50^{\circ}, 30^{\circ}, 20^{\circ}, 15^{\circ}, 10^{\circ}, 7^{\circ}, 5^{\circ}$, and $3^{\circ}$ ) with the atmospheric information provided from ERA-Interim. The performance of the mapping functions and gradient models was assessed by comparing the SHD and SWD calculated using Equations (1) and (2) with the models obtained using the ray-tracing technique. Notably, the ZHD and ZWD used in Equations (1) and (2) were determined with the ERA-Interim dataset. To study the temporal and spatial properties of these mapping functions and gradient models, experiments were conducted in six regions, including the temperate zone, Qinghai-Tibet Plateau, Equator, Sahara Desert, Amazon Rainforest, and North Pole, for four seasons.

\section{Data and Methodology}

In this study, the ray-tracing technique was adopted to calculate the SHD and SWD at different elevations and azimuth angles with atmospheric information from the ERA-Interim dataset, which has a horizontal resolution of $0.75^{\circ} \times 0.75^{\circ}$ and a vertical resolution of 37 levels, with a top level of $1 \mathrm{hPa}$, and is available at $0,6,12$, and 18 Universal Time Coordinated (UTC) [64]. The pressure-level data are global grid data for geopotential, absolute temperature, specific humidity, and pressure (hPa). More details on the ray-tracing technique, mapping functions, and gradient models involved in this study are presented in the following subsections. Three mapping functions, NMF [57], GMF [58], and 
VMF1 [59], and three gradient models, including Macmillan [49], Chen and Herring [50], and Meindl, Schaer, Hugentobler and Beutler [51], are presented. The ray-tracing technique that was adopted to determine the propagation path of the electromagnetic signal considered as a ray is introduced in Section 2.3 [65].

\subsection{Mapping Function}

Marini [54] proposed a mapping function form with a continued fraction, which was then adopted by Niell [57], Böhm, Niell, Tregoning and Schuh [58], and Böhm, Werl and Schuh [59] by extending the form of the continued fraction to three terms. The mapping function is dependent on the elevation of the observation, which can be written as follows:

$$
m_{i}(\varepsilon)=\frac{1+\frac{a_{i}}{1+\frac{b_{i}}{1+c_{i}}}}{\sin \varepsilon+\frac{a_{i}}{\sin \varepsilon+\frac{b_{i}}{\sin \varepsilon+c_{i}}}}(i=h, w),
$$

where $a_{i}, b_{i}$, and $c_{i}$ are different coefficients, designated by indices of " $h$ " (hydrostatic) or " $w$ " (wet). Each of the GMF, NMF, and VMF1 implementations follow this form by adopting different values for the coefficients.

For the NMF [57], the coefficients were determined using one-year meteorological data from 26 radiosonde stations mostly around the Northern Hemisphere, as well as the temperature and relative humidity profiles of the U.S. standard atmosphere for the northern latitudes of $15^{\circ}, 30^{\circ}, 45^{\circ}, 60^{\circ}$, and $75^{\circ}$ in January and July. The coefficients of the NMF hydrostatic mapping function depend on the latitude, height of the site, and day of the year, while the coefficient of the wet mapping functions depends on the latitude.

Böhm (2006) published the GMF [58] considering the problem of the time delay of the VMF1 coefficients. Further, GMF has good agreement with VMF1, which is also an empirical function of the coordinates and day of the year. Moreover, compared with NMF, GMF has few annual errors and small regional height biases.

For the VMF [66], the coefficients $b_{h}$ and $c_{h}$ were determined based on the method of ray-tracing through the global grid data of ECMWF ERA40. VMF1 [59] is an update version of VMF [66]. Coefficient $b_{h}$ is assigned a new value, and coefficient $c_{h}$ is redefined as a function of the latitude and Julian day to correct the systematic errors of VMF related to climate zone and seasonality.

To investigate the effects of different mapping functions on the determination of STD, we first calculated STD using the following Equation (4):

$$
\operatorname{STD}(\varepsilon)=m_{h}(\varepsilon) \cdot \mathrm{ZHD}+m_{w}(\varepsilon) \cdot \mathrm{ZWD}+\delta,
$$

where ZHD and ZWD were calculated from the ERA-Interim dataset with Equation (28), and $\delta$ is the residual, which is the unmodeled tropospheric delay.

\subsection{Gradient Model}

As mentioned above, the mapping function links the tropospheric delay in the zenith and slant directions in different directions without considering atmospheric asymmetry. The gradient models, which are a function of the azimuth, are an effective way to account for the atmospheric asymmetry effect.

Chen and Herring [50] and Herring [56] proposed a gradient model based on the "tilted" atmosphere assumption, which can be expressed as the first term of the gradient mapping function [67]:

$$
G\left(G_{N}, G_{E}, \varepsilon, \alpha\right)=m_{g}(\varepsilon)\left(G_{N} \cos \alpha+G_{E} \sin \alpha\right)
$$


where $G$ represents the gradient model; and $G_{N}$ and $G_{E}$ are the north-south and east-west gradient parameters, respectively.

$$
m_{g}(\varepsilon)=\frac{1}{\sin \varepsilon t a n \varepsilon+C^{\prime}}
$$

where $C$ is a constant of $0.0032[50,56]$.

MacMillan (1995) [61] proposed a gradient model similar to the previous one by replacing $m_{g}(\varepsilon)$ with $m(\varepsilon) \cot \varepsilon$ :

$$
G\left(G_{N}, G_{E}, \varepsilon, \alpha\right)=m(\varepsilon) \cot \varepsilon\left(G_{N} \cos \alpha+G_{E} \sin \alpha\right),
$$

where $m(\varepsilon)$ is a mapping function. Although the MTT dry mapping function was adopted as $m(\varepsilon)$ in Macmillan's study, Macmillan also indicated that no obvious changes were observed when a hydrostatic or wet mapping function was adopted.

Meindl, Schaer, Hugentobler and Beutler [51] proposed another gradient model using a zenith angle $z$ between the propagating path of satellite signals and the tropospheric zenith direction (i.e., the direction in which the tropospheric delay is at its minimum) to replace the angle $\widetilde{z}$ between the propagating path of the satellite signals and the geometrical zenith direction to represent a "tilted" atmosphere:

$$
G\left(G_{N}, G_{E}, \varepsilon, \alpha\right)=\frac{\partial f}{\partial z}\left(G_{N} \cos \alpha+G_{E} \sin \alpha\right),
$$

where $z$ is the tropospheric zenith angle and $\frac{\partial f}{\partial z}$ is the derivative of the arbitrary mapping function with respect to the zenith angle $z$.

To investigate the effects of different gradient models on the determination of STD, we first calculated STD using the following Equation (9):

$$
\operatorname{STD}(\varepsilon, \alpha)=m_{h}(\varepsilon) \mathrm{ZHD}+m_{w}(\varepsilon) \mathrm{ZWD}+G\left(G_{N}, G_{E}, \varepsilon, \alpha\right)+\Delta,
$$

where $G$ represents the gradient model; $G_{N}$ and $G_{E}$ are the north-south and east-west gradient parameters, which need to be estimated together with the zenith delay in GNSS data processing; and $\Delta$ is the residual, which is the unmodeled tropospheric delay.

\subsection{Ray-Tracing}

Ray-tracing is a technique for reconstructing the ray path with a three-dimensional refractivity field based on geometrical optics theory. Although the 3D ray-tracing method can provide a very accurate result for the retrieved ray path, it is time-consuming in an elliptical coordinate frame (i.e., WGS84) [68,69]. Normally, the 3D ray-tracing method can be reduced to a $2 \mathrm{D}$ method by fixing the azimuth of the ray path. Compared woth the 3D method, 2D ray-tracing can produce a comparable accuracy with much less computation complexity. Considering the complexity of the ray-tracing implemented in an elliptical coordinate, an approximation of the Euler radius can be carried out in a local spherical coordinate, which can produce a high ray-tracing result with much less calculation time $[63,69,70]$.

According to the Euler formula, the Euler radius of the local spherical coordinate is written as

$$
R_{\alpha}=\frac{M N}{M \sin ^{2} \alpha+N \cos ^{2} \alpha},
$$

where $\alpha, M$, and $N$ are the azimuth, the meridian, and the prime radii of curvature, respectively. $M$ and $N$ are defined by the latitude $\varphi$ at the starting point $P_{1}$ (see Figure 1 ) and are given by

$$
M=\frac{a\left(1-e^{2}\right)}{\left(1-e^{2} \sin ^{2} \varphi\right)^{\frac{3}{2}}},
$$




$$
N=\frac{a}{\left(1-e^{2} \sin ^{2} \varphi\right)^{\frac{1}{2}}},
$$

where $a$ and $e$ are the semi-major axis and the first eccentricity of the reference ellipsoid (i.e., WGS84) [71], respectively.
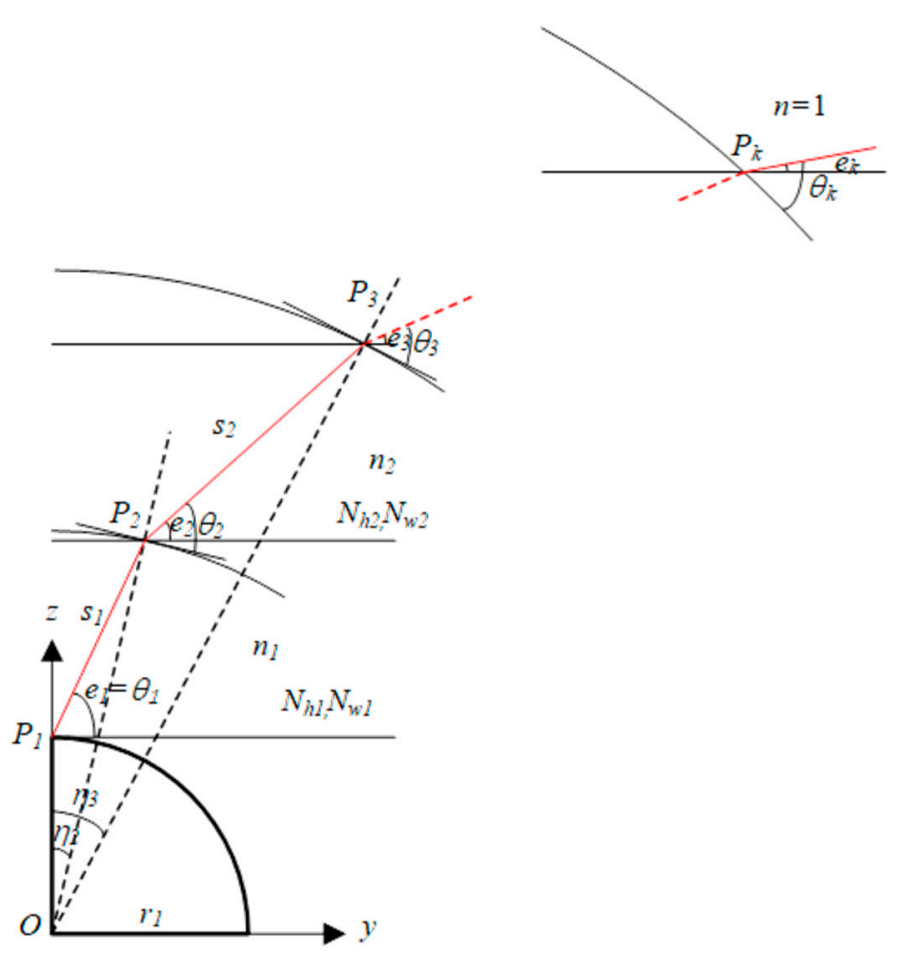

Figure 1. Geometry of ray-tracing with the piecewise-linear (PWL) approach.

The piecewise-linear (PWL) approach adopted in this study is a simple and effective 2D ray-tracing algorithm [72]. As shown in Figure 1, the $y-z$ plane, where the PWL approach is implemented, is defined by the geometric center of the Earth $O$, the starting point $P_{1}$, and the puncture point of the electromagnetic signal and the top troposphere $P_{k}$. The $z$-axis joins the geometric center, the origin point, of the Earth with the starting point $P_{1}$. The $y$-axis is orthogonal to the $z$-axis and restricted to the observation direction defined by the azimuth angle $\alpha$. The $\theta_{i}, \eta_{i}$, and $e_{i}$ for $i=1,2, \ldots, k$ denote the tangent angles defined by the ray trajectory and the height layer, the geometric angles to the ray points $P_{i}$, and the elevation angles at the height layer, respectively. The refractive index at the $i$-th layer is indicated as $n_{i}$. Here, the subscript $i$ of $i=1,2, \ldots, k-1$ is the layer index of the PWL approach and the height layer. In the loop of the PWL approach, based on the geometric rules and Snell's Law, the calculations are as follows:

$$
\begin{gathered}
s_{i}=-r_{i} \sin \theta_{i}+\sqrt{r_{i+1}^{2}-r_{i}^{2} \cos ^{2} \theta_{i}}, \\
z_{i+1}=z_{i}+s_{i} \operatorname{sine}_{i}, \\
y_{i+1}=y_{i}+s_{i} \cos e_{i}, \\
\eta_{i+1}=\arctan \frac{y_{i+1}}{z_{i+1}}, \\
\theta_{i+1}=\arccos \left(\frac{n_{i}}{n_{i+1}} \cos \left(\theta_{i}+\eta_{i+1}-\eta_{i}\right)\right), \\
e_{i+1}=\theta_{i+1}-\eta_{i+1},
\end{gathered}
$$


with the initial conditions $\theta_{1}=e_{1}, z_{1}=r_{1}, y_{1}=0$, and $\eta_{1}=0$. In the first layer of ray-tracing, the elevation angle $e_{1}$ at starting point $P_{1}$ is determined based on the following [63]:

$$
e_{1}=\varepsilon+\Delta g_{\text {apbend }}
$$

where $\Delta g_{\text {apbend }}$ is the a priori value of the bending angle, which can be calculated with the following [69]:

$$
\Delta g_{\text {apbend }}\left(\varepsilon, h_{0}\right)[d e g]=\frac{C_{b} \exp \left(-\frac{h_{0}}{6000}\right)}{\tan \varepsilon},
$$

where $h_{0}$ is the ellipsoidal (geodetic) height of the starting point (in meters), and $C_{b}$ is the empirical constant set to 0.02 .

Before starting the ray-tracing calculation, the refractive indices $n_{i}$ used in Equation (17) must first be defined from an atmospheric model (e.g., the ECMWF meteorological data). The refractive indices $n_{i}$ or the refractivity $N$ can be calculated with Equation (21), proposed by Thayer [73]:

$$
N=10^{6}(n-1)=k_{1} \frac{P_{d}}{T} Z_{d}^{-1}+k_{2} \frac{P_{w}}{T} Z_{w}^{-1}+k_{3} \frac{P_{d}}{T^{2}} Z_{w}^{-1},
$$

where $P_{d}$ and $P_{w}$ are the pressure of dry air and water vapor $(\mathrm{hPa})$, respectively; $T$ is the temperature in Kelvin; $Z_{d}$ and $Z_{w}$ are the compressibility factors for dry air and water vapor, respectively, which can be calculated with

$$
\begin{gathered}
Z_{d}^{-1}=1+P_{d}\left(57.97 \cdot 10^{-8}\left(1+\frac{0.52}{T}\right)-9.4611 \cdot 10^{-4} \frac{T-273.15}{T^{2}}\right), \\
Z_{w}^{-1}=1+1650 \frac{P_{w w}}{T^{3}}\left(1-0.01317(T-273.15)+1.75 \times 10^{-4}(T-273.15)^{2}+1.44\right. \\
\left.\times 10^{-6}(T-273.15)^{3}\right),
\end{gathered}
$$

respectively, as suggested by Owens [74].

The $k_{1}, k_{2}$, and $k_{3}$ in Equation (21) are three empirical constants, which were set to the "best average" values, $77.6890(\mathrm{~K} / \mathrm{hPa}), 71.2952(\mathrm{~K} / \mathrm{hPa})$, and 375,463 $\left(\mathrm{K}^{2} / \mathrm{hPa}\right)$, respectively, as calculated by Rüeger [75] and suggested by Nafisi, et al. [76].

According to Böhm, et al. [77] and Wallace and Hobbs [78], the water vapor pressure can be expressed as

$$
P_{w}=\frac{q p}{\psi+(1-\psi) q}
$$

where $p$ is the atmospheric pressure; and $\psi$ is the ratio between the gas constant of dry air $R_{d}$ and the gas constant of water vapor $R_{w}$, defined as $\psi=R_{d} / R_{w}=0.622$.

As mentioned above, a geodetic reference system is needed for the ray-tracing algorithms adopted in this study; therefore, the geopotentials in the ERA-Interim dataset needed to be transformed to ellipsoidal heights following the procedures given in previous studies (see the works of $[77,79,80]$ ).

First, the geopotential height $h_{d}$ can be calculated with

$$
h_{d}=\frac{Z}{g_{n}},
$$

where $g_{n}$ is a constant gravity value and was set to $9.80665 \mathrm{~m} / \mathrm{s}^{2}$ [77].

Then, the orthometric (geometric) height can be calculated as follows:

$$
\begin{aligned}
& h_{\text {orth }} \\
& =\frac{1}{2 \cdot 1.57 \cdot 10^{-7}} \\
& -\sqrt{\frac{1}{\left(2 \cdot 1.57 \cdot 10^{-7}\right)^{2}}-\frac{1}{1.57 \cdot 10^{-7}} \frac{h_{d}}{1-0.0026373 \cos (2 \varphi)+0.0000059 \cos ^{2}(2 \varphi)}} .
\end{aligned}
$$


Finally, the ellipsoidal height $h_{\text {ell }}$ can be determined by Fotopoulos [81]

$$
h_{\text {ell }}=h_{\text {orth }}+h_{N}
$$

where $h_{N}$ is the geoid undulation, which was obtained from the Earth Gravitational Model 2008 [80].

\subsection{Methods}

Two sets of STDs, SHDs, and SWDs are calculated in this study. One set is derived by applying the ray-tracing program to the ERA-Interim dataset to determine the slant delays at different elevations and azimuths. Using the equations given in Section 2.3, the ray-tracing-derived STD, SHD, and SWD can be calculated, according to the work of [72], as

$$
\begin{gathered}
\mathrm{STD}=\sum_{i=1}^{k-1}\left[\left(n_{i}-1\right) s_{i}\right]+g_{\text {bend }}, \\
\mathrm{SHD}=\sum_{i=1}^{k-1}\left[\left(n_{h, i}-1\right) s_{i}\right], \\
\mathrm{SWD}=\sum_{i=1}^{k-1}\left[\left(n_{w, i}-1\right) s_{i}\right],
\end{gathered}
$$

where $g_{b e n d}$ is the tropospheric delay caused by the bending effect calculated with the following Equation (31) [72]:

$$
g_{\text {bend }}=\sum_{i=1}^{k-1}\left[s_{i}-\cos \left(e_{i}-e_{k}\right) s_{i}\right],
$$

where $g_{b e n d}$ is the tropospheric delay caused by the bending effect; and $n_{h}$ and $n_{w}$ are the hydrostatic and wet indices, respectively, which were determined, following the works of [48] and [72], as

$$
\begin{gathered}
n_{h}=1+\left(k_{1} \frac{R}{M_{d}}\right) \times 10^{-6}, \\
n_{w}=1+\left(k_{2}^{\prime} \frac{P_{w}}{T}+k_{3} \frac{P_{w}}{T^{2}}\right) \times 10^{-6},
\end{gathered}
$$

where $k_{2}^{\prime}$ is the refractivity empirical constant defined as $k_{2}^{\prime}=k_{2}-k_{1} \psi$; and $R$ and $M_{d}$ are the universal gas constant and molar mass of dry air, set to $8314.510 \mathrm{~J} / \mathrm{kmol} \cdot \mathrm{K}$ and $28.9644 \mathrm{~g} / \mathrm{mol}$, respectively [82,83]. In addition to the slant delay, the zenith equivalent delay (ZTD, ZHD, and ZWD) can be calculated at a $90^{\circ}$ elevation using Equations (28)-(30).

The other set uses ray-tracing to calculate the ZHD and ZWD first and then calculates the SHD and SWD using Equations (28)-(30). The STDs, SHDs, and SWDs calculated by ray-tracing directly are regarded as the benchmark values in this study to assess the accuracy of the slant delays determined with Equations (4) or (9). To investigate the performance of these mapping functions and gradient models for different regions and seasons, a comparison was conducted in the six typical regions listed in Table 1 for January, April, July, and October. For each region, the ray-tracing calculations were run at nine or ten selected grid points at eight azimuths $\left(0^{\circ}, 45^{\circ}, 90^{\circ}, 135^{\circ}, 180^{\circ}, 225^{\circ}, 270^{\circ}\right.$, and $\left.315^{\circ}\right)$ and 10 elevations $\left(90^{\circ}, 70^{\circ}, 50^{\circ}, 30^{\circ}, 20^{\circ}, 15^{\circ}, 10^{\circ}, 7^{\circ}, 5^{\circ}\right.$, and $\left.3^{\circ}\right)$. As the performance of mapping functions are closely related to regional climate characteristics, especially the variation of water vapor, the comparison studies were conducted in the abovementioned six regions with very different climate conditions. It should be noted that the height of the grids in the Qinghai-Tibet region is set to $4500 \mathrm{~m}$. This is because, as the world's largest and highest plateau, the Qinghai-Tibet region's average elevations exceeds $4500 \mathrm{~m}$. 
Table 1. The six regions and coordinates in the scheme (the notations " $\mathrm{N}$ ", " $\mathrm{S}$ ", " $\mathrm{E}$ ", and " $\mathrm{W}$ " indicate northern latitude, southern latitude, eastern longitude, and western longitude, respectively).

\begin{tabular}{ccccc}
\hline Region & Latitude Range & Longitude Range & Number of Grids & Height of Grids (m) \\
\hline Temperature Zone & $33^{\circ} \mathrm{N}-36^{\circ} \mathrm{N}$ & $115^{\circ} \mathrm{E}-117^{\circ} \mathrm{E}$ & 9 & 200 \\
Qinghai-Tibet & $29.5^{\circ} \mathrm{N}-32.5^{\circ} \mathrm{N}$ & $88.5^{\circ} \mathrm{E}-91.5^{\circ} \mathrm{E}$ & 9 & 4500 \\
Plateau & $1.5^{\circ} \mathrm{S}-1.5^{\circ} \mathrm{N}$ & $144^{\circ} \mathrm{E}-147^{\circ} \mathrm{E}$ & 9 & 200 \\
Equator & $18^{\circ} \mathrm{N}-21^{\circ} \mathrm{N}$ & $1.5^{\circ} \mathrm{W}-1.5^{\circ} \mathrm{E}$ & 9 & 200 \\
Sahara Desert & $2.5^{\circ} \mathrm{S}-5.5^{\circ} \mathrm{S}$ & $66^{\circ} \mathrm{E}-69^{\circ} \mathrm{E}$ & 9 & 200 \\
Amazon Rainforest & $85.5^{\circ} \mathrm{N}-90^{\circ} \mathrm{N}$ & $1.5^{\circ} \mathrm{W}-1.5^{\circ} \mathrm{E}$ & 10 & 200 \\
North Pole & &
\end{tabular}

\section{Results}

In this study, the effects of various mapping functions and gradient models on STD determinations were studied and discussed in detail. In Section 3.1, the variation of the water vapor in six regions was studied. In Section 3.2, the performances of the three mapping functions for the different seasons in the six selected regions were compared. In Section 3.3, the performances of the three gradient models were investigated, and the improvements in the STD estimates with or without the gradient model were studied. In Section 3.4, the bending effect of the GNSS signal propagation, which is normally ignored in GNSS remote sensing or positioning, was studied.

\subsection{Variation of $P W V$}

As the performance of mapping functions is closely related to water vapor variation, the temporal characteristics of PWV in these six regions are studied in this subsection. Figure 2 shows the variation of PWV during 2018. It can be clearly seen that the annual variation of PWV is much larger in the temperate zone and Sahara Desert than that in the Qinghai-Tibet plateau and the North Pole. Although the PWV value is very high in the Equator and the Amazon Rainforest region, the annual variation is not very strong. The black lines in Figure 2 represent the fitting model obtained with the following Equation (34):

$$
\begin{aligned}
\mathrm{PWV}=a_{0}+a_{1} \cos (2 \pi & \left.\frac{d o y}{365.25}\right)+a_{2} \sin \left(2 \pi \frac{d o y}{365.25}\right)+a_{3} \cos \left(4 \pi \frac{d o y}{365.25}\right) \\
& +a_{4} \sin \left(4 \pi \frac{d o y}{365.25}\right),
\end{aligned}
$$

where doy is the day of the year; $a_{0}$ is the mean value; and $\left(a_{1}, a_{2}\right)$ and $\left(a_{3}, a_{4}\right)$ are the annual and semi-annual amplitude, respectively.

As shown in Figure 2 and Table 2, the largest mean value of PWV is found in the region of the Equator, with a value of $53.34 \mathrm{~mm}$, and the smallest value is found in the North Pole, with a value of only $5.23 \mathrm{~mm}$. The annual amplitude of PWV in the temperate zone is as large as $23.17 \mathrm{~mm}$, while it is only $0.62 \mathrm{~mm}$ in the Equator region. However, the PWV in the Equator shows a very strong monthly variation.

Table 2. The mean value, annual amplitude, and semi-annual amplitude of precipitable water vapor (PWV) in the six regions.

\begin{tabular}{cccc}
\hline Region & Annual Mean PWV (mm) & Annual Amplitude (mm) & Semi-Annual Amplitude (mm) \\
\hline Temperature Zone & 23.17 & 19.98 & 5.62 \\
Qinghai-Tibet Plateau & 6.40 & 7.22 & 2.64 \\
Equator & 53.34 & 0.62 & 1.03 \\
Sahara Desert & 21.57 & 5.36 & 14.68 \\
Amazon Rainforest & 44.85 & 1.81 & 2.96 \\
North Pole & 5.23 & 4.05 & 1.38 \\
\hline
\end{tabular}



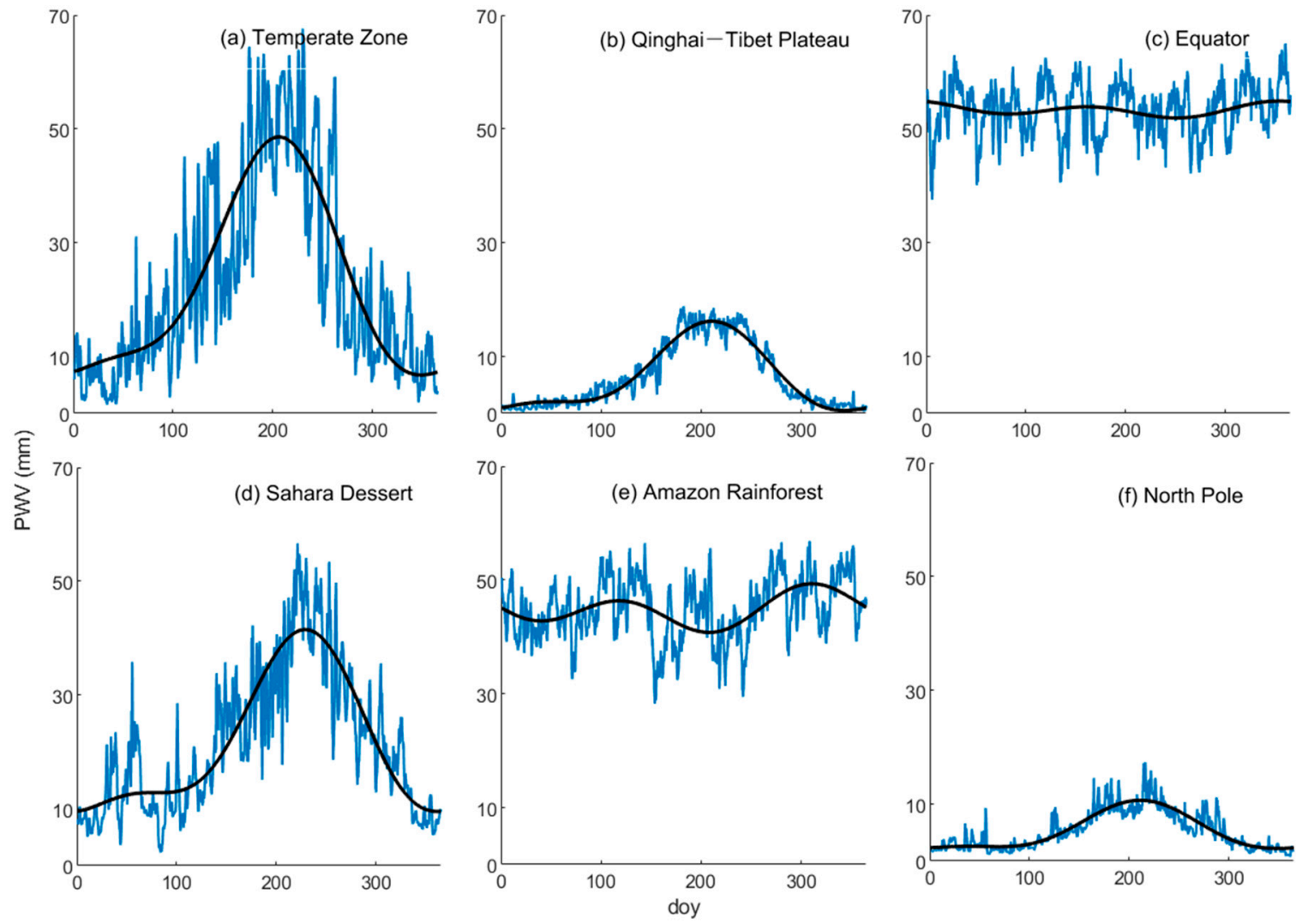

Figure 2. Variation of precipitable water vapor (PWV) in the selected six regions during 2018. doy, day of year: (a) Temperate Zone (b) Qinghai-Tibet Plateau (c) Equator (d) Sahara Dessert (e) Amazon Rainforest (f) North Pole.

\subsection{Mapping Function}

Three widely used mapping functions (i.e., NMF, GMF, or VMF1) were adopted in this study, and the STDs at the abovementioned nine elevations were calculated with Equation (4) and compared to the benchmark values determined using the ray-tracing program.

As shown in Figure 3, both the RMS and bias show a marked dependence on the elevations in all six regions. The RMS and bias are calculated with

$$
\begin{aligned}
\text { RMS } & =\sqrt{\frac{1}{N} \sum_{i=1}^{N}\left(S T D_{\text {ray-tracing }}-S T D_{M+(G)}\right)^{2}}, \\
\text { bias } & =\frac{1}{N} \sum_{i=1}^{N}\left(S T D_{\text {ray-tracing }}-S T D_{M+(G)}\right),
\end{aligned}
$$

where $S T D_{\text {ray-tracing }}$ and $S T D_{M+(G)}$ are the STD calculated by Equations (4), (9), and (28)-(30); the $R M S_{M}$ represents the RMS error of the STD determined with a mapping function only; and $R M S_{G+M}$ represents the RMS error of the STD determined with a mapping function and gradient model, which is studied in the following subsection.

For the three mapping functions, the RMSs of the STD are all smaller than $2 \mathrm{~mm}$ above the $30^{\circ}$ elevation and smaller than $9 \mathrm{~mm}$ above the $15^{\circ}$ elevation, but show a significant increase below $15^{\circ}$. For example, in the temperate zone, the RMS value increases from approximately $35 \mathrm{~mm}$ at the $10^{\circ}$ elevation to approximately $160 \mathrm{~mm}$ at the $3^{\circ}$ elevation. The value of the RMS also shows an obvious dependence on the regions. In the Qinghai-Tibet Plateau region, the largest RMS value is approximately $50 \mathrm{~mm}$, while in the other regions, the largest values are all greater than $100 \mathrm{~mm}$. 
This result might be because the variation in the atmosphere in the Qinghai-Tibet Plateau region is not as great as that in the other regions, and thus can be modeled more accurately. A similar phenomenon can also be observed in the North Pole region, where the water vapor content is much lower than that in other regions, such as the Equator regions. In terms of RMS, these three mapping functions show similar performance above a $15^{\circ}$ elevation. However, for the elevations below $15^{\circ}$, compared with the GMF and NMF, the VMF1 mapping function performs better, especially below the $7^{\circ}$ elevation. The NMF has a much larger RMS at low elevations than at high elevations, and the RMS was two times greater than that of VMF1 in the North Pole region at $3^{\circ}$ elevations.

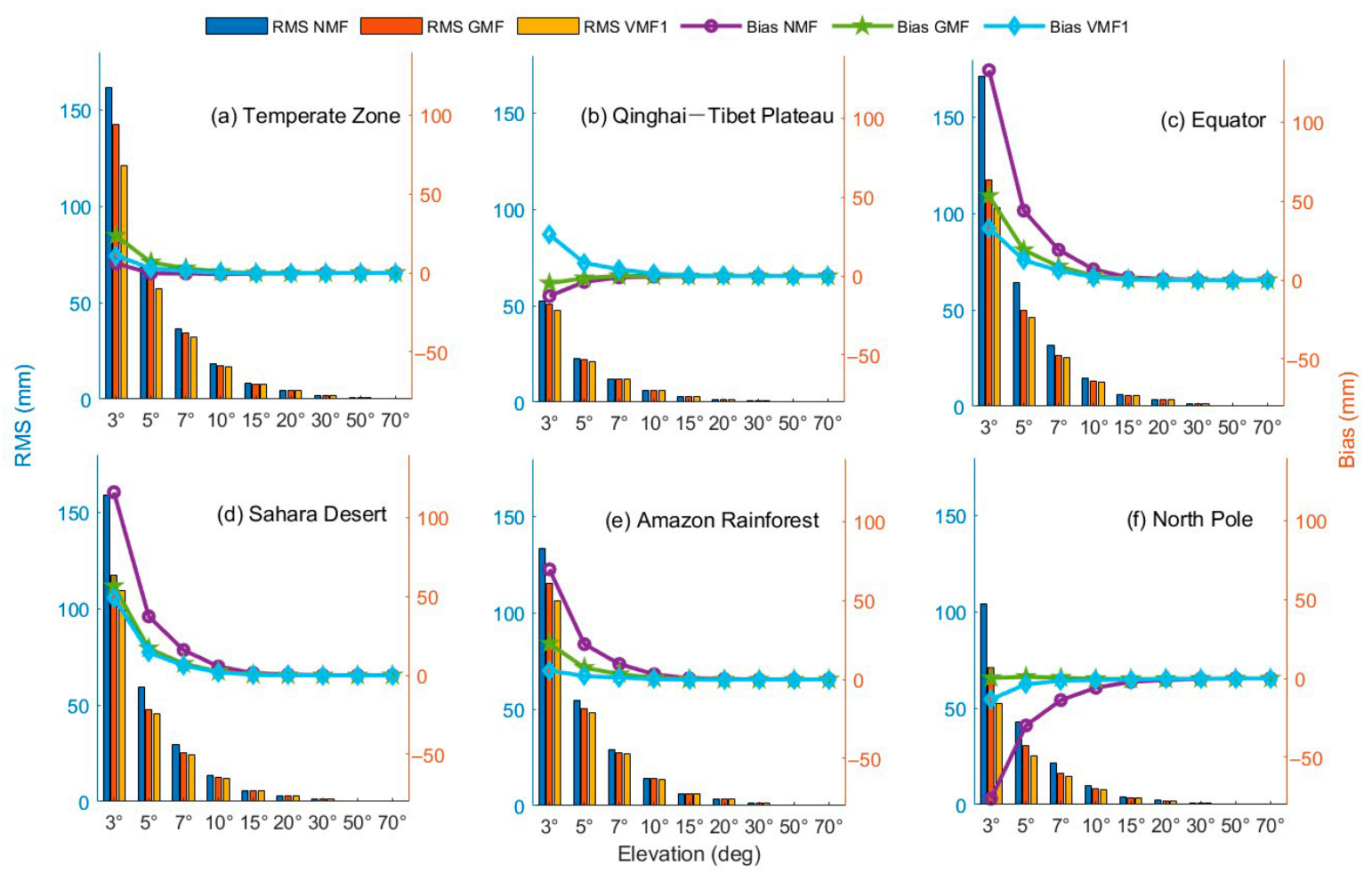

Figure 3. The root-mean-squares (RMSs) and biases of the NMF, GMF, andVMF1 for the six regions at the nine elevations $\left(70^{\circ}, 50^{\circ}, 30^{\circ}, 20^{\circ}, 15^{\circ}, 10^{\circ}, 7^{\circ}, 5^{\circ}\right.$, and $\left.3^{\circ}\right)$ : (a) Temperate Zone (b) Qinghai-Tibet Plateau (c) Equator (d) Sahara Dessert (e) Amazon Rainforest (f) North Pole.

In terms of both the RMS and bias, above $15^{\circ}$, the mapping functions considered in this study perform relatively similarly in the selected six regions. However, at low elevations, the performances of these three mapping functions are substantially different, and VMF1 has a higher accuracy than those of the other two mapping functions.

Table 3 shows that the biases at different azimuths have clear discrepancies, especially in the north-south direction, with biases exceeding those in the east-west direction. Thus, at low elevations, the biases do not fluctuate around the value of zero. The biases of NMF and GMF for the Qinghai-Tibet Plateau and the biases at the North Pole are lower than zero, which may be because of the lack of enough meteorological data for the region in the ECMWF reanalysis data.

Figure 4 shows the RMS and bias of STD derived with VMF1 in January, April, July, and October. For the regions located in the Northern Hemisphere (i.e., the temperature zone, the Sahara Desert, and the Qinghai-Tibet Plateau), it is obvious that the RMS values and biases are larger during the summer than during the winter. For the Equator region, the RMS value is obviously greater in January and October than in April and July. For the North Pole, the RMS errors are larger in July and October than in January and April. This result confirms that the performance of VMF1 is highly correlated with both the season and location. 
Table 3. The biases of the slant total delays (STDs) from Vienna mapping function (VMF1) with respect to the STDs from ray tracing at different azimuths.

\begin{tabular}{cccccccc}
\hline Azimuth & Temperate Zone & Qinghai-Tibet Plateau & Equator & Sahara Desert & Amazon Rainforest & North Pole \\
\hline $0^{\circ}$ & 101.1 & 72.4 & 60.8 & 118.1 & 61.8 & -7.8 \\
\hline $90^{\circ}$ & 1.2 & 17.1 & 18.9 & 34.6 & -17.0 & -9.7 \\
\hline $180^{\circ}$ & -49.1 & -0.3 & 41.5 & 13.9 & -10.1 & -24.2 \\
\hline $270^{\circ}$ & -7.8 & 16.1 & 11.8 & 30.8 & -11.6 & -11.7 \\
\hline
\end{tabular}

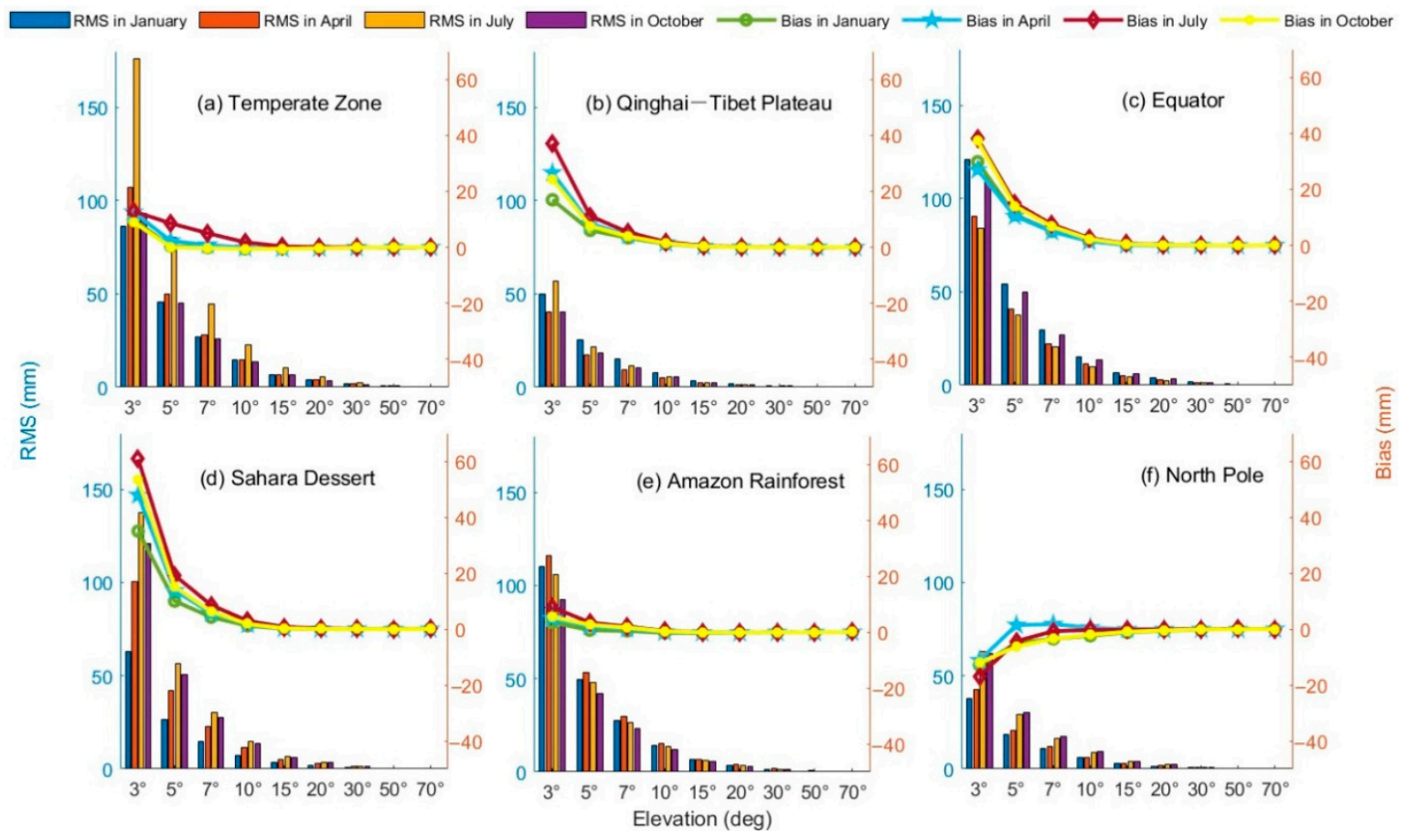

Figure 4. The RMSs and biases of VMF1 for the six regions at the different elevations $\left(70^{\circ}, 50^{\circ}, 30^{\circ}, 20^{\circ}\right.$, $15^{\circ}, 10^{\circ}, 7^{\circ}, 5^{\circ}$, and $3^{\circ}$ ): (a) Temperate Zone (b) Qinghai-Tibet Plateau (c) Equator (d) Sahara Dessert (e) Amazon Rainforest (f) North Pole.

\subsection{Gradient Model}

Three widely used gradient models were discussed in Section 2.2, and their performance will be studied in this section.

In Equation (9), the STDs at the nine elevations and six azimuths were calculated using the ray-tracing program, after which the $G_{N}$ and $G_{E}$ were estimated using the least-square method. Using the ray-tracing-derived STD as a reference, the RMSs and biases of the STD derived with the mapping function plus the gradient model are shown in Figure 5. Notably, VMF1, which is more accurate than the other two mapping functions, was adopted in Equation (9).

The blue bar and yellow line are the RMS and bias, respectively, of the STD determined with VMF1 without the gradient model. All three gradient models studied show very similar performances in the six selected regions.

A statistic of the improvement in STD accuracy was calculated with the following Equation (37), and the results are shown in Table 4.

$$
\text { Accuracy Improvement }=\frac{R M S_{M}-R M S_{G+M}}{R M S_{M}},
$$

where $R M S_{M}$ indicates the RMS of the STD determined with the VMF1 mapping function only, while $R M S_{G+M}$ is derived with the VMF1 mapping function together with the Meindl gradient model. 


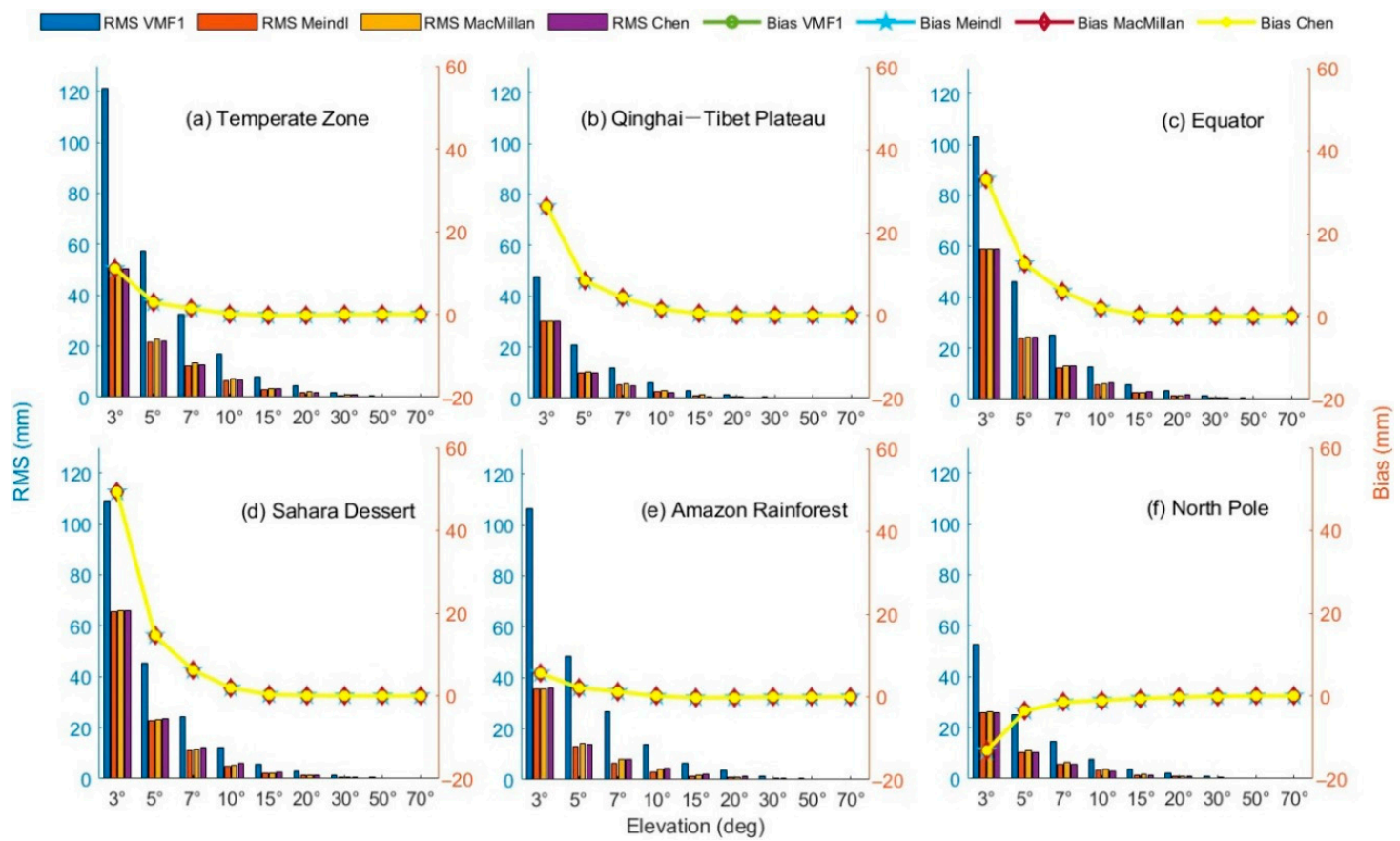

Figure 5. The RMSs and biases of VMF1 and VMF1 with three gradient models for the six regions at the nine elevations $\left(70^{\circ}, 50^{\circ}, 30^{\circ}, 20^{\circ}, 15^{\circ}, 10^{\circ}, 7^{\circ}, 5^{\circ}, 3^{\circ}\right)$ in four seasons: (a) Temperate Zone (b) Qinghai-Tibet Plateau (c) Equator (d) Sahara Dessert (e) Amazon Rainforest (f) North Pole.

Table 4. The accuracy improvement in VMF1 owing to the adoption of the Meindl gradient model.

\begin{tabular}{|c|c|c|c|c|c|c|}
\hline Elevation & Temperate Zone (\%) & Qinghai-Tibet Plateau (\%) & Equator (\%) & Sahara Desert (\%) & Amazon Rainforest (\%) & North Pole $(\%)$ \\
\hline $3^{\circ}$ & 59.11 & 36.64 & 42.78 & 39.92 & 66.73 & 51.65 \\
\hline $7^{\circ}$ & 62.84 & 57.70 & 50.46 & 54.00 & 75.97 & 62.17 \\
\hline $15^{\circ}$ & 62.87 & 64.86 & 56.85 & 61.18 & 77.91 & 60.53 \\
\hline $20^{\circ}$ & 62.75 & 65.62 & 57.54 & 61.62 & 77.76 & 61.08 \\
\hline $30^{\circ}$ & 62.21 & 64.44 & 57.68 & 61.51 & 78.18 & 61.30 \\
\hline $50^{\circ}$ & 61.07 & 56.62 & 51.44 & 55.46 & 67.26 & 53.19 \\
\hline
\end{tabular}

As the performances of the three mapping functions are similar, only the improvement results for the Meindl, Schaer, Hugentobler and Beutler [51] gradient model are shown in Table 4. From Table 4, we find that the accuracy improvement ranges from $37 \%$ to $79 \%$ owing to the adoption of the Meindl, Schaer, Hugentobler and Beutler [51] gradient model. Therefore, the inclusion of a gradient model is useful for reducing STD estimation errors. However, the STD error is still as large at 10-20 $\mathrm{mm}$ at a $5^{\circ}$ elevation owing to the unmodeled atmospheric inhomogeneity. Notably, as the ZHD and ZWD in this study are calculated from the atmospheric reanalysis data, the errors in the ZHD and ZWD can be neglected. The STD error discussed in this study can be regarded as an error caused by an error in the mapping function and gradient model. In terms of bias, the inclusion of a gradient model in the estimation of STD seems to have no obvious benefit in reducing the bias.

Figure 6 presents the RMSs and biases for the six regions in the four seasons and indicates that the RMS errors and biases have an obvious seasonal variation in the temperate zone, the Qinghai-Tibet Plateau, and the Sahara Desert. The seasonal variations in RMS errors are similar to the findings stated in Section 3.1; that is, both the RMSs and biases are larger in the summer than in the winter. This phenomenon is most obvious in the temperate zone, where the RMS error in July is approximately 2-3 times that in April and October and approximately 3-4 times that in January. Figure 6 also shows that the biases are all positive, except in the North Pole region. This result indicates that the ray-tracing-derived STD is normally larger than the value obtained with the ZHD and ZWD mapping 
functions and the gradient model. One possible reason for these positive biases is the bending effect, which will be discussed in the following subsection.

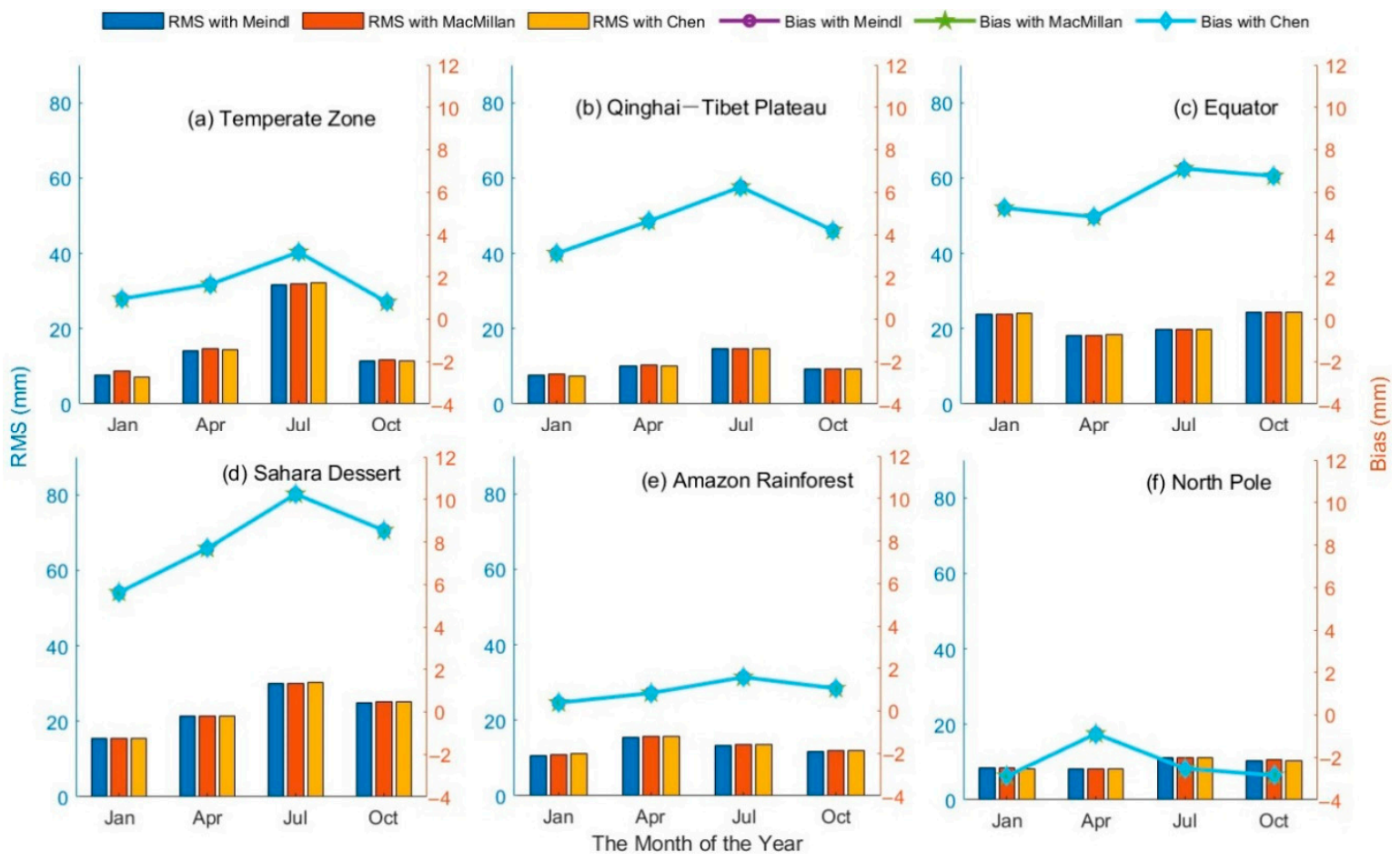

Figure 6. The RMSs and biases for the six regions in the four seasons: (a) Temperate Zone (b) Qinghai-Tibet Plateau (c) Equator (d) Sahara Dessert (e) Amazon Rainforest (f) North Pole.

Figure 7 illustrates that, in most regions, the error of SWD is larger than that of SHD.
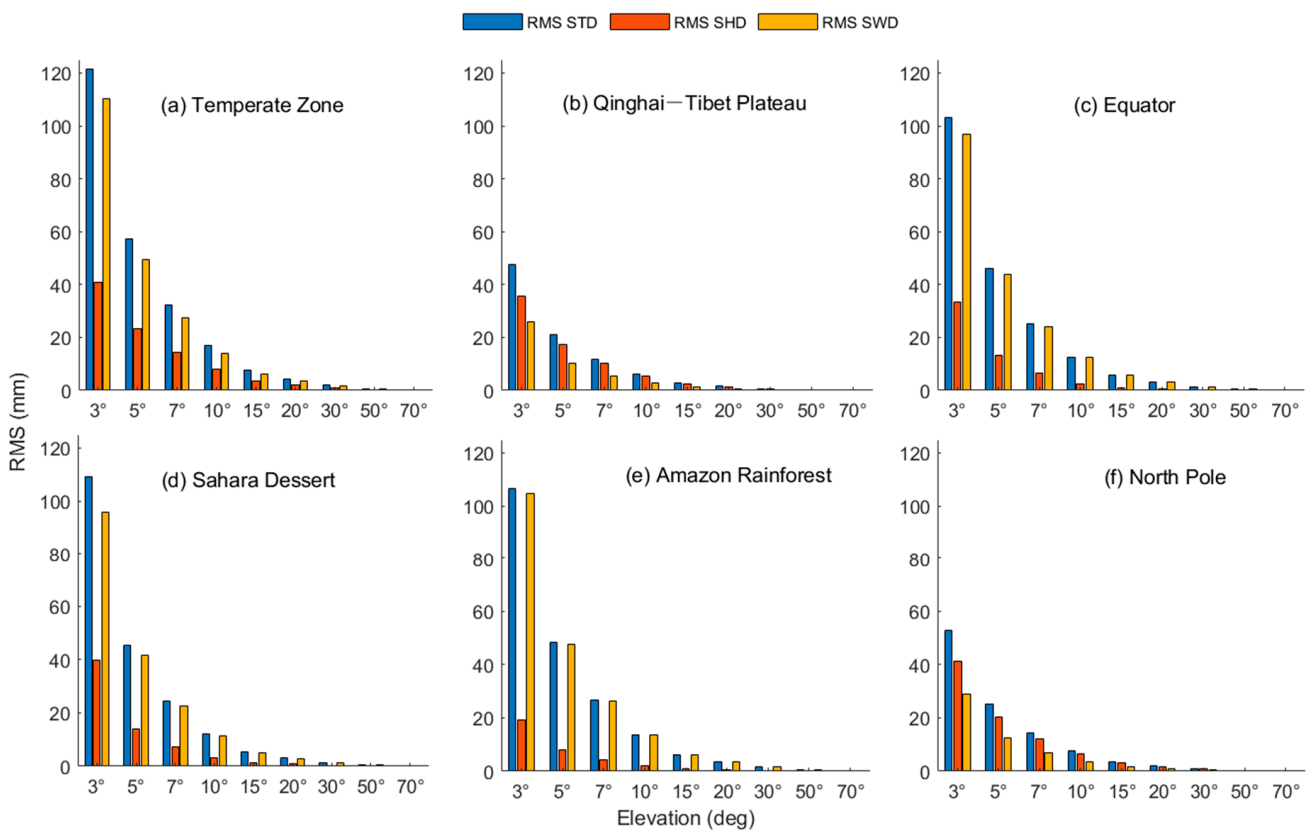

Figure 7. The RMSs of STD, SHD, and SWD for the six regions at the different elevations $\left(70^{\circ}, 50^{\circ}, 30^{\circ}\right.$, $20^{\circ}, 15^{\circ}, 10^{\circ}, 7^{\circ}, 5^{\circ}$, and $3^{\circ}$ ): (a) Temperate Zone (b) Qinghai-Tibet Plateau (c) Equator (d) Sahara Dessert (e) Amazon Rainforest (f) North Pole. 


\subsection{Bending Effect}

As shown in Figure 1, a neutral atmosphere will affect the GNSS signal in two ways: (1) the signal will travel at a speed less than that in a vacuum, and (2) the signal will be bent owing to atmospheric refraction caused by the vertical changes in atmospheric density $[84,85]$. To investigate the effect of the bending on determining the STD, the delay caused by the bending effect in the six regions for the different months was calculated by Equation (31). As shown in Figure 1, $i$ denotes the $i$-th height layer; $s_{i}$ is the distance of the ray point $P_{i}$; and the next ray point, $P_{i+1}, e_{1}$, is the actual starting elevation angle; while $e_{k}$ is the actual ending elevation angle. All these values can be determined during the ray-tracing procedure.

Figure 8 shows that the tropospheric delay caused by the bending effect is normally below $13 \mathrm{~mm}$ above a $15^{\circ}$ elevation. However, this value increases dramatically from approximately $40 \mathrm{~mm}$ at a $10^{\circ}$ elevation to approximately $200 \mathrm{~mm}$ at a $5^{\circ}$ elevation and even reaches $500-700 \mathrm{~mm}$ at a $3^{\circ}$ elevation in most regions, which means that this effect becomes nonnegligible at low elevations, especially tropospheric tomography. The bending effect on the Qinghai-Tibet Plateau is much smaller than that on the other regions because the height of the Qinghai-Tibet Plateau is normally above $4 \mathrm{~km}$, and thus the tropospheric delay is smaller than that in the other regions because of a shorter signal propagation travel distance in the troposphere. The results in Figure 8 also indicate that the bending effect does not have a clear dependence on season.

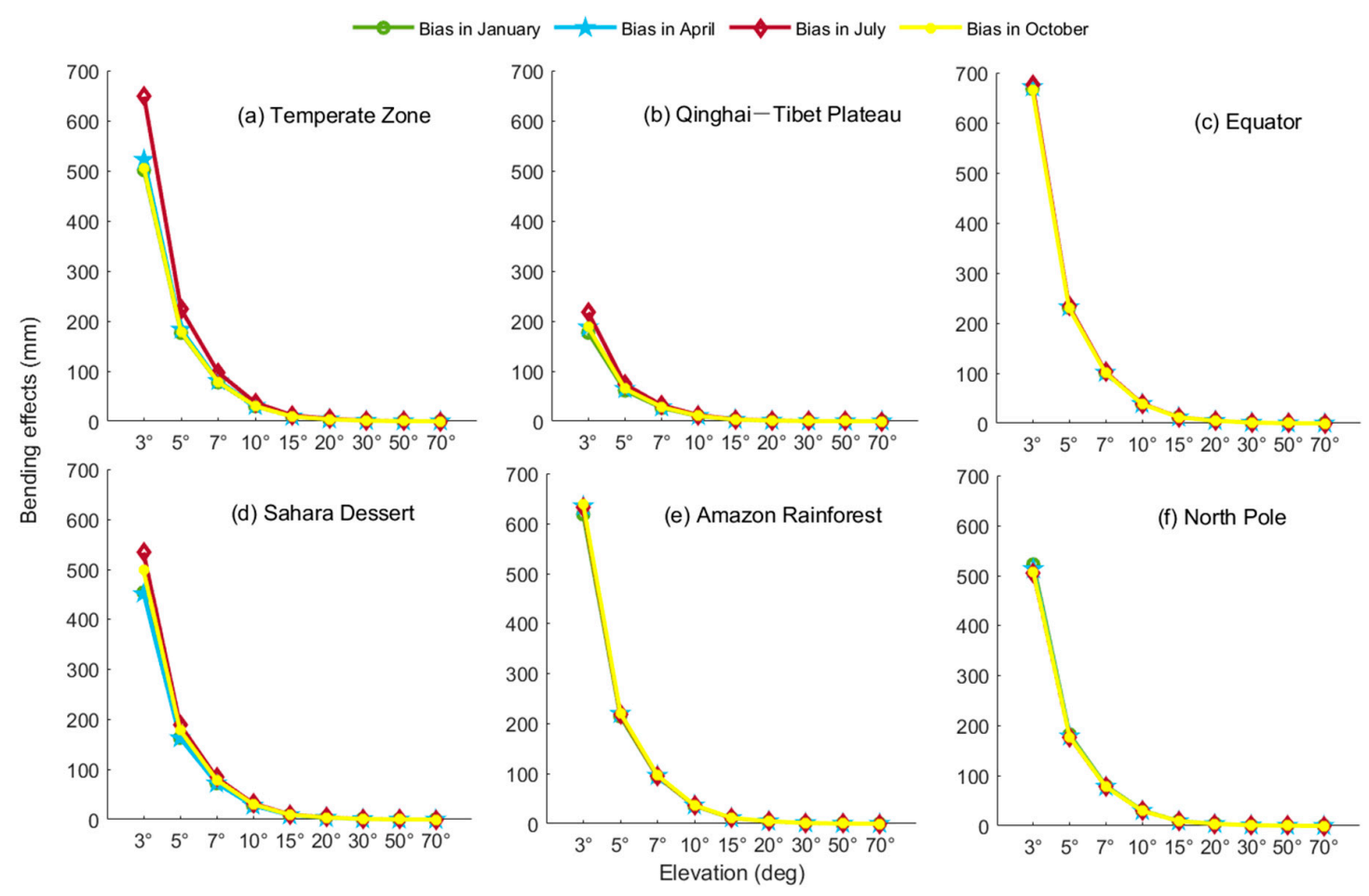

Figure 8. The bending effects for the six regions at different elevations $\left(70^{\circ}, 50^{\circ}, 30^{\circ}, 20^{\circ}, 15^{\circ}, 10^{\circ}, 7^{\circ}\right.$, $5^{\circ}$, and $3^{\circ}$ ): (a) Temperate Zone (b) Qinghai-Tibet Plateau (c) Equator (d) Sahara Dessert (e) Amazon Rainforest (f) North Pole.

\section{Discussions}

The performance of three mapping functions and three gradient models was studied comprehensively in this study. As suggested in the study, at low elevations, the performances of these three mapping functions are substantially different, and VMF1 has higher accuracy than that of the other two mapping functions. This means that, in the GNSS data processing, if the cutoff angle was set to $15^{\circ}$, then all three mapping functions would yield a similar result. However, if the cutoff angle was set to a value less than $15^{\circ}$, then the VMF1 mapping function would always be recommended in 
GNSS data processing. The performance of the mapping functions shows a very strong dependence on the location and the season. The RMS values and biases are obviously larger during the summer than during the winter. This is because the water vapor is greater and has more complex variation in the summer than in the winter, which makes it more difficult to accurately model the relationship between tropospheric delay in the zenith direction and slant direction. In addition, the RMS is much larger in the regions with a large PWV value (e.g., the Equator) than in regions with a small PWV value (e.g., the North Pole). The comparison shows that all three gradient models have very similar performance in the six selected regions. The adoption of the gradient models improved the accuracy of the STD. For example, in the temperate zone, the RMS error of the STD decreased from approximately $120 \mathrm{~mm}$ to approximately $50 \mathrm{~mm}$ at the $3^{\circ}$ elevation and from approximately $60 \mathrm{~mm}$ to approximately $20 \mathrm{~mm}$ at the $5^{\circ}$ elevation. Although the inclusion of a gradient model is useful for improving the accuracy of the STD, its error is still as large at $10 \sim 20 \mathrm{~mm}$ at a $5^{\circ}$ elevation owing to the unmodeled atmospheric inhomogeneity. In addition, although the coefficients of the VMF1 were determined using the observations at $3.2^{\circ}, 5^{\circ}, 7^{\circ}, 10^{\circ}, 15^{\circ}, 20^{\circ}, 30^{\circ}, 50^{\circ}, 70^{\circ}$, and $90^{\circ}$ elevations, which will, to a certain degree, account for the bending effect, the nonlinear variation in the bending effect with the elevations still results in a large source of error in the determination of the STD using the mapping functions.

\section{Conclusions}

The accuracy of GNSS-derived STD is closely related to the adopted mapping functions and gradient models. In this study, the performances of various types of mapping functions (i.e., NMF, GMF, and VMF1) and gradient models (i.e., Chen, MacMillan, and Meindl) were assessed in six regions with typical climate conditions (the temperate zone, Qinghai-Tibet Plateau, Equator, Sahara Desert, Amazon Rainforest, and North Pole). The STD calculated with the ray-tracing technique from ERA-Interim is used as a reference to assess the STD calculated with ZHD, ZWD, and various mapping functions plus gradient models. Both the ZHD and ZWD are also calculated from the ERA-Interim. We first compared the STD derived with zenith delay and three types of mapping functions (i.e., NMF, GMF, and VMF1) to the STD derived with the ray-tracing method. Notably, in the first experiment, no gradient model was included in the determination of the STD. The results show that all three mapping functions perform similarly above $15^{\circ}$ in terms of their RMS and bias, but VMF1 performs better than the other two mapping functions below a $15^{\circ}$ elevation. This study also indicates that the performances of the mapping functions clearly depend on the season. For example, for the regions located in the Northern Hemisphere (i.e., the temperate zone, the Sahara Desert, and the Qinghai-Tibet Plateau), the RMS values and biases are larger during the summer than during the winter. This result occurs because the water vapor amount is greater and has more complex variation in the summer than in the winter, which makes it more difficult to accurately model the relationship between tropospheric delay in the zenith direction and slant direction.

In the second experiment, three types of gradient models and the VMF1 were included to determine the STD. The results show that all three types of gradient models perform similarly in the six selected regions. The inclusion of gradient models can significantly improve the accuracy of STD compared with the STD determined without gradient models. In most regions, this improvement is approximately $50 \%-60 \%$, but in the Amazon rainforest, this improvement is approximately $74 \%$. The results also show that the RMS of the STD has an obvious seasonal variation in the temperate zone, the Qinghai-Tibet Plateau, and the Sahara Desert regions. The SWD error is larger than that of the SHD in most regions.

This study shows that, although the coefficients of the VMF1 will, to a certain degree, account for the bending effect, the nonlinear variation in the bending effect with elevation still represents a large source of error in the determination of STD using the mapping functions.

Author Contributions: Conceptualization, C.Q.; Formal analysis, C.Q. and X.W.; Investigation, C.Q., X.W., Resources, S.Z., J.Z. and H.L.; Software, C.Q., X.W. and S.Z.; Visualization, H.Y. and Z.L.; Writing一original draft, 
C.Q., X.W. and H.Y.; supervision, X.W.; project administration, X.W.; funding acquisition, X.W. and Z.L. All authors have read and agreed to the published version of the manuscript.

Funding: This project is funded by the Beijing Natural Science Foundation (8184092), Strategic Priority Research Program of the Chinese Academy of Sciences (No. XDA17010304), CAS Pioneer Hundred Talents Program, National Key Research and Development Plan (no. 2016YFB0501405), the National Key Research Program of China "Collaborative Precision Positioning Project" (No. 2016YFB0501900), China Natural Science Funds (Nos. 41904033, 41674043, 41704038, 41730109), Beijing Nova Program (xx2017042), National High Technology Research and Development Program of China (No. 2015AA124101), Young Top-Notch Talents Team Program of Beijng Excellent Talents Founding (No.2017000021223ZK13).

Acknowledgments: The atmospheric reanalysis dataset ERA-Interim provided by the European Centre For Medium-Range Weather Forecasts (ECMWF). Thanks to Daniel Landskron for the helpful communication via Email and constructive suggestions.

Conflicts of Interest: The authors declare no conflict of interest.

\section{References}

1. Bevis, M.; Businger, S.; Herring, T.A.; Rocken, C.; Anthes, R.A.; Ware, R.H. GPS meteorology: Remote sensing of atmospheric water vapor using the global positioning system. J. Geophys. Res. Atmos. 1992, 97, 15787-15801. [CrossRef]

2. Lay, O.P. Phase calibration and water vapor radiometry for millimeter-wave arrays. Astron. Astrophys. Suppl. Ser. 1997, 122, 547-557. [CrossRef]

3. Rocken, C.; Ware, R.; Hove, T.V.; Solheim, F.; Alber, C.; Johnson, J.; Bevis, M.; Businger, S. Sensing atmospheric water vapor with the Global Positioning System. Geophys. Res. Lett. 1993, 20, 2631-2634. [CrossRef]

4. Rocken, C.; Hove, T.V.; Johnson, J.; Solheim, F.; Ware, R.; Bevis, M.; Chiswell, S.; Businger, S. GPS/STORM-GPS sensing of atmospheric water vapor for meteorology. J. Atmos. Ocean. Technol. 1995, 12, 468-478. [CrossRef]

5. Li, X.; Dick, G.; Ge, M.; Heise, S.; Wickert, J.; Bender, M. Real-time GPS sensing of atmospheric water vapor: Precise point positioning with orbit, clock, and phase delay corrections. Geophys. Res. Lett. 2014, 41, 3615-3621. [CrossRef]

6. Li, X.; Dick, G.; Lu, C.; Ge, M.; Nilsson, T.; Ning, T.; Wickert, J.; Schuh, H. Multi-GNSS Meteorology: Real-Time Retrieving of Atmospheric Water Vapor From BeiDou, Galileo, GLONASS, and GPS Observations. IEEE Trans. Geosci. Remote Sens. 2015, 53, 6385-6393. [CrossRef]

7. Liu, Z.; Li, M.; Zhong, W.; Wong, M.S. An approach to evaluate the absolute accuracy of WVR water vapor measurements inferred from multiple water vapor techniques. J. Geodyn. 2013, 72, 86-94. [CrossRef]

8. Liu, Z.; Wong, M.S.; Nichol, J.; Chan, P. A multi-sensor study of water vapour from radiosonde, MODIS and AERONET: A case study of Hong Kong. Int. J. Climatol. 2013, 33, 109-120. [CrossRef]

9. Li, M.; Li, W.; Shi, C.; Zhao, Q.; Su, X.; Qu, L.; Liu, Z. Assessment of precipitable water vapor derived from ground-based BeiDou observations with Precise Point Positioning approach. Adv. Space Res. 2015, 55, 150-162. [CrossRef]

10. Li, Z.; Muller, J.P.; Cross, P. Comparison of precipitable water vapor derived from radiosonde, GPS, and Moderate-Resolution Imaging Spectroradiometer measurements. J. Geophys. Res. Atmos. 2003, 108. [CrossRef]

11. Wilgan, K.; Rohm, W.; Bosy, J. Multi-observation meteorological and GNSS data comparison with Numerical Weather Prediction model. Atmos. Res. 2015, 156, 29-42. [CrossRef]

12. Yao, Y.B.; Shan, L.L.; Zhao, Q.Z. Establishing a method of short-term rainfall forecasting based on GNSS-derived PWV and its application. Sci. Rep. 2017, 7, 11. [CrossRef] [PubMed]

13. Zhao, Q.; Yao, Y.; Yao, W. GPS-based PWV for precipitation forecasting and its application to a typhoon event. J. Atmos. Sol.-Terr. Phys. 2018, 167, 124-133. [CrossRef]

14. Zhang, K.; Manning, T.; Wu, S.; Rohm, W.; Silcock, D.; Choy, S. Capturing the Signature of Severe Weather Events in Australia Using GPS Measurements. IEEE J. Sel. Top. Appl. Earth Obs. Remote Sens. 2015, 8, 1839-1847. [CrossRef]

15. Businger, S.; Chiswell, S.R.; Bevis, M.; Duan, J.; Anthes, R.; Rocken, C.; Ware, R.; Exner, M.; Vanhove, T.; Solheim, F. The Promise of GPS in Atmospheric Monitoring. Bull. Am. Meteorol. Soc. 1996, 77, 5-18. [CrossRef] 
16. Wang, X.; Zhang, K.; Wu, S.; Fan, S.; Cheng, Y. Water vapor-weighted mean temperature and its impact on the determination of precipitable water vapor and its linear trend. J. Geophys. Res. Atmos. 2016, 121, 833-852. [CrossRef]

17. Wang, X.; Zhang, K.; Wu, S.; Li, Z.; Cheng, Y.; Li, L.; Yuan, H. The correlation between GNSS-derived precipitable water vapor and sea surface temperature and its responses to El Niño-Southern Oscillation. Remote Sens. Environ. 2018, 216, 1-12. [CrossRef]

18. Chen, B.; Liu, Z. Global water vapor variability and trend from the latest 36 year (1979 to 2014) data of ECMWF and NCEP reanalyses, radiosonde, GPS, and microwave satellite. J. Geophys. Res. Atmos. 2016, 121, 11-442. [CrossRef]

19. Kuo, Y.-H.; Guo, Y.-R.; Westwater, E.R. Assimilation of precipitable water measurements into a mesoscale numerical model. Mon. Weather Rev. 1993, 121, 1215-1238. [CrossRef]

20. Kuo, Y.-H.; Zou, X.; Guo, Y.-R. Variational Assimilation of Precipitable Water Using a Nonhydrostatic Mesoscale Adjoint Model. Part. I: Moisture Retrieval and Sensitivity Experiments. Mon. Weather Rev. 1996, 124, 122-147. [CrossRef]

21. Bender, M.; Dick, G.; Ge, M.; Deng, Z.; Wickert, J.; Kahle, H.-G.; Raabe, A.; Tetzlaff, G. Development of a GNSS water vapour tomography system using algebraic reconstruction techniques. Adv. Space Res. 2011, 47, 1704-1720. [CrossRef]

22. Kawabata, T.; Shoji, Y. Applications of GNSS Slant Path Delay Data on Meteorology at Storm Scales. In Multifunctional Operation and Application of GPS; IntechOpen: London, UK, 2018.

23. Ha, S.-Y.; Kuo, Y.-H.; Guo, Y.-R.; Lim, G.-H. Variational Assimilation of Slant-Path Wet Delay Measurements from a Hypothetical Ground-Based GPS Network. Part. I: Comparison with Precipitable Water Assimilation. Mon. Weather Rev. 2003, 131, 2635-2655. [CrossRef]

24. Seko, H.; Kawabata, T.; Tsuyuki, T.; Nakamura, H.; Koizumi, K.; Iwabuchi, T. Impacts of GPS-derived water vapor and radial wind measured by Doppler radar on numerical prediction of precipitation. J. Meteorol. Soc. Jpn. Ser. II 2004, 82, 473-489. [CrossRef]

25. Bauer, H.-S.; Wulfmeyer, V.; Schwitalla, T.; Zus, F.; Grzeschik, M. Operational assimilation of GPS slant path delay measurements into the mm5 4DVAR system. Tellus A Dyn. Meteorol. Oceanogr. 2011, 63, 263-282. [CrossRef]

26. Kawabata, T.; Shoji, Y.; Seko, H.; Saito, K. A numerical study on a mesoscale convective system over a subtropical island with 4D-Var assimilation of GPS slant total delays. J. Meteorol. Soc. Jpn. Ser. II 2013, 91, 705-721. [CrossRef]

27. Rocken, C.; Braun, J.; Meertens, C.; Ware, R.; Sokolovskiy, S.; Van Hove, T. Water Vapor Tomography with Low Cost GPS Receivers [Presentation]; Department of Energy: Tucson, AZ, USA, 1998.

28. Braun, J.; Rocken, C.; Meertens, C.; Ware, R. Development of a water vapor tomography system using low cost L1 GPS receivers. In Proceedings of the 9th ARM Science Team Meeting Proceedings, San Antonio, TX, USA, 22-26 March 1999.

29. Rohm, W.; Bosy, J. Local tomography troposphere model over mountains area. Atmos. Res. 2009, 93, 777-783. [CrossRef]

30. Chen, B.; Liu, Z. Voxel-optimized regional water vapor tomography and comparison with radiosonde and numerical weather model. J. Geod. 2014, 88, 691-703. [CrossRef]

31. Flores, A.; Ruffini, G.; Rius, A. 4D tropospheric tomography using GPS slant wet delays. In Annales Geophysicae; Springer: Berlin/Heidelberg, Germany, 2000.

32. Nilsson, T.; Gradinarsky, L. Water vapor tomography using GPS phase observations: Simulation results. IEEE Trans. Geosci. Remote Sens. 2006, 44, 2927-2941. [CrossRef]

33. Heublein, M.; Zhu, X.X.; Alshawaf, F.; Mayer, M.; Bamler, R.; Hinz, S. Compressive sensing for neutrospheric water vapor tomography using GNSS and InSAR observations. In Proceedings of the 2015 IEEE International Geoscience and Remote Sensing Symposium (IGARSS), Milan, Italy, 26-31 July 2015; IEEE: Piscataway, NJ, USA, 2015.

34. Yao, Y.; Zhao, Q. Maximally using GPS observation for water vapor tomography. IEEE Trans. Geosci. Remote Sens. 2016, 54, 7185-7196. [CrossRef]

35. Benevides, P.; Nico, G.; Catalão, J.; Miranda, P.M. Analysis of galileo and GPS integration for GNSS tomography. IEEE Trans. Geosci. Remote Sens. 2017, 55, 1936-1943. [CrossRef] 
36. Dong, Z.; Jin, S. 3-D Water Vapor Tomography in Wuhan from GPS, BDS and GLONASS Observations. Remote Sens. 2018, 10, 62. [CrossRef]

37. Zhao, Q.; Yao, Y.; Cao, X.; Zhou, F.; Xia, P. An Optimal Tropospheric Tomography Method Based on the Multi-GNSS Observations. Remote Sens. 2018, 10, 234. [CrossRef]

38. Gradinarsky, L.P.; JarLemark, P. Ground-based GPS tomography of water vapor: Analysis of simulated and real data. J. Meteorol. Soc. Jpn. Ser. II 2004, 82, 551-560. [CrossRef]

39. Bender, M.; Dick, G.; Wickert, J.; Ramatschi, M.; Ge, M.; Gendt, G.; Rothacher, M.; Raabe, A.; Tetzlaff, G. Estimates of the information provided by GPS slant data observed in Germany regarding tomographic applications. J. Geophys. Res. Atmos. 2009, 114, D0630. [CrossRef]

40. Jin, S.; Cardellach, E.; Xie, F. GNSS Remote Sensing: Theory, Methods and Applications; Springer: Dordrecht, The Netherlands, 2014.

41. Zhang, H.; Yuan, Y.; Li, W.; Ou, J.; Li, Y.; Zhang, B. GPS PPP-derived precipitable water vapor retrieval based on Tm/Ps from multiple sources of meteorological data sets in China. J. Geophys. Res. Atmos. 2017, 122, 4165-4183. [CrossRef]

42. Realini, E.; Tsuda, T.; Sato, K.; Oigawa, M.; Iwaki, Y. Analysis of the temporal and spatial variability of the wet troposphere at a local scale by high-rate PPP using a dense GNSS network. In Proceedings of the 25th International Technical Meeting of the Satellite Division of the Institute of Navigation (Ion Gnss 2012), Nashville, TN, USA, 17-21 September 2012; pp. 3406-3412.

43. Mendez Astudillo, J.; Lau, L.; Tang, Y.-T.; Moore, T. Analysing the Zenith Tropospheric Delay Estimates in On-line Precise Point Positioning (PPP) Services and PPP Software Packages. Sensors 2018, 18, 580. [CrossRef]

44. Yuan, Y.; Zhang, K.; Rohm, W.; Choy, S.; Norman, R.; Wang, C.S. Real-time retrieval of precipitable water vapor from GPS precise point positioning. J. Geophys. Res. Atmos. 2014, 119, 10044-10057. [CrossRef]

45. Shi, J.; Xu, C.; Li, Y.; Gao, Y. Impacts of real-time satellite clock errors on GPS precise point positioning-based troposphere zenith delay estimation. J. Geod. 2015, 89, 747-756. [CrossRef]

46. Zhao, Q.; Yao, Y.; Yao, W.; Li, Z. Real-time precise point positioning-based zenith tropospheric delay for precipitation forecasting. Sci. Rep. 2018, 8, 7932. [CrossRef]

47. Li, X.; Zus, F.; Lu, C.; Dick, G.; Ning, T.; Ge, M.; Wickert, J.; Schuh, H. Retrieving of atmospheric parameters from multi-GNSS in real time: Validation with water vapor radiometer and numerical weather model. J. Geophys. Res. Atmos. 2015, 120, 7189-7204. [CrossRef]

48. Davis, J.L.; Herring, T.A.; Shapiro, I.I.; Rogers, A.E.E.; Elgered, G. Geodesy by radio interferometry: Effects of atmospheric modeling errors on estimates of baseline length. Radio Sci. 1985, 20, 1593-1607. [CrossRef]

49. Macmillan, D.S. Atmospheric gradients from very long baseline interferometry observations. Geophys. Res. Lett. 1995, 22, 1041-1044. [CrossRef]

50. Chen, G.; Herring, T.A. Effects of atmospheric azimuthal asymmetry on the analysis of space geodetic data. J. Geophys. Res. Solid Earth 1997, 102, 20489-20502. [CrossRef]

51. Meindl, M.; Schaer, S.; Hugentobler, U.; Beutler, G. Tropospheric Gradient Estimation at CODE: Results from Global Solutions. J. Meteorol. Soc. Japan. Ser. II 2004, 82, 331-338. [CrossRef]

52. Elgered, G.; Davis, J.; Herring, T.; Shapiro, I. Geodesy by radio interferometry: Water vapor radiometry for estimation of the wet delay. J. Geophys. Res. Solid Earth 1991, 96, 6541-6555. [CrossRef]

53. Wang, X.; Zhang, K.; Wu, S.; He, C.; Cheng, Y.; Li, X. Determination of zenith hydrostatic delay and its impact on GNSS-derived integrated water vapor. Atmos. Meas. Tech. 2017, 10, 2807-2820. [CrossRef]

54. Marini, J.W. Correction of satellite tracking data for an arbitrary tropospheric profile. Radio Sci. 1972, 7, 223-231. [CrossRef]

55. Ifadis, I. The Atmospheric Delay of Radio Waves: Modelling the Elevation Dependence on a Global Scale; Technical Report; Chalmers University of Technology: Göteborg, Sweden, 1986.

56. Herring, T.A. Modeling atmospheric delays in the analysis of space geodetic data. In Publications on Geodesy Proceedings of Refraction of Transatmospheric Signals in Geodesy; Nederlandse Commissie voor Geodesie: Amersfoort, The Netherlands, 1992; Volume 36, pp. 157-164.

57. Niell, A.E. Global mapping functions for the atmosphere delay at radio wavelengths. J. Geophys. Res. 1996, 101, 3227-3246. [CrossRef]

58. Böhm, J.; Niell, A.; Tregoning, P.; Schuh, H. Global Mapping Function (GMF): A New Empirical Mapping Function based on Numerical Weather Model Data. 2006. Available online: https://agupubs.onlinelibrary. wiley.com/action/showCitFormats?doi=10.1029\%2F2005GL025546 (accessed on 20 December 2019). 
59. Böhm, J.; Werl, B.; Schuh, H. Troposphere mapping functions for GPS and very long baseline interferometry from European Centre for Medium-Range Weather Forecasts operational analysis data. J. Geophys. Res. Solid Earth 2006, 111. [CrossRef]

60. Lu, C.; Li, X.; Li, Z.; Heinkelmann, R.; Nilsson, T.; Dick, G.; Ge, M.; Schuh, H. GNSS tropospheric gradients with high temporal resolution and their effect on precise positioning. J. Geophys. Res. Atmos. 2016, 121, 912-930. [CrossRef]

61. MacMillan, D.S.; Ma, C. Atmospheric gradients and the VLBI terrestrial and celestial reference frames. Geophys. Res. Lett. 1997, 24, 453-456. [CrossRef]

62. Pany, T. Measuring and modeling the slant wet delay with GPS and the ECMWF NWP model. Phys. Chem. EarthParts A/B/C 2002, 27, 347-354. [CrossRef]

63. Hofmeister, A. Determination of Path Delays in the Atmosphere for Geodetic VLBI by Means of Ray-Tracing. Ph.D. Thesis, Department of Geodesy and Geoinformation, Wien, Austria, 2016.

64. Berrisford, P.; Dee, D.P.; Poli, P.; Brugge, R.; Mark, F.; Manuel, F.; Kållberg, P.W.; Kobayashi, S.; Uppala, S.; Adrian, S. The ERA-Interim Archive Version 2.0; ECMWF: Shinfield Park, UK, 2011.

65. Bean, B.R.; Dutton, E. Radio Meteorology; Dover Publications: Washington, DC, USA, 1966.

66. Böhm, J.; Schuh, H. Vienna Mapping Functions. In Proceedings of the 16th EVGA Working Meeting, Leipzig, Germany, 9-10 May 2003.

67. Zus, F.; Douša, J.; Kačmař́k, M.; Václavovic, P.; Balidakis, K.; Dick, G.; Wickert, J. Improving GNSS Zenith Wet Delay Interpolation by Utilizing Tropospheric Gradients: Experiments with a Dense Station Network in Central Europe in the Warm Season. Remote Sens. 2019, 11, 674. [CrossRef]

68. Thayer, G. A rapid and accurate ray tracing algorithm for a horizontally stratified atmosphere. Radio Sci. 1967, 2, 249-252. [CrossRef]

69. Hobiger, T.; Ichikawa, R.; Koyama, Y.; Kondo, T. Fast and accurate ray-tracing algorithms for real-time space geodetic applications using numerical weather models. J. Geophys. Res. Atmos. 2008, 113, 1-14. [CrossRef]

70. Zus, F.; Bender, M.; Deng, Z.; Dick, G.; Heise, S.; Shang-Guan, M.; Wickert, J. A methodology to compute GPS slant total delays in a numerical weather model. Radio Sci. 2012, 47,1-15. [CrossRef]

71. National Imagery and Mapping Agency. Department of Defense World Geodetic System 1984: Its Definition and Relationships with Local Geodetic Systems; National Imagery and Mapping Agency: St. Louis, MO, USA, 2000.

72. Böhm, J. Troposphärische Laufzeitverzögerungen in der VLBI; Institutfür Geodäsie und Geophysik, Fakultät fur Mathematik und Geoinformation, Technische Universität Wien: Vienna, Austria, 2004.

73. Thayer, G.D. An improved equation for the radio refractive index of air. Radio Sci. 1974, 9, 803-807. [CrossRef]

74. Owens, J.C. Optical Refractive Index of Air: Dependence on Pressure, Temperature and Composition. Appl. Opt. 1967, 6, 51-59. [CrossRef]

75. Rüeger, J.M. Refractive index formulae for radio waves. In Proceedings of the FIG XXII International Congress, Washington, DC, USA, 19-26 April 2002; FIG: Washington, DC, USA, 2002.

76. Nafisi, V.; Urquhart, L.; Santos, M.C.; Nievinski, F.G.; Bohm, J.; Wijaya, D.D.; Schuh, H.; Ardalan, A.A.; Hobiger, T.; Ichikawa, R.; et al. Comparison of Ray-Tracing Packages for Troposphere Delays. IEEE Trans. Geosci. Remote Sens. 2012, 50, 469-481. [CrossRef]

77. Böhm, J.; Salstein, D.; Alizadeh, M.M.; Wijaya, D.D. Geodetic and Atmospheric Background. In Atmospheric Effects in Space Geodesy; Böhm, J., Schuh, H., Eds.; Springer: Berlin/Heidelberg, Germany, 2013; pp. 1-33.

78. Wallace, J.M.; Hobbs, P.V. Atmospheric Thermodynamics. In Atmospheric Science, 2nd ed.; Wallace, J.M., Hobbs, P.V., Eds.; Academic Press: San Diego, CA, USA, 2006; pp. 63-111.

79. Kraus, H. Die Atmosphare "der Erde: Eine Einfu"hrung in die Meteorologie. [Erscheinungsort nicht ermittelbar]; Springer: Berlin/Heidelberg, Germany, 2004.

80. Pavlis, N.K.; Holmes, S.A.; Kenyon, S.C.; Factor, J.K. The development and evaluation of the Earth Gravitational Model. 2008 (EGM2008). J. Geophys. Res. Solid Earth 2012, 117, B04406.

81. Fotopoulos, G. An Analysis on the Optimal Combination of Geoid, Orthometric and Ellipsoidal Height Data. Ph.D. Thesis, University of Calgary, Department of Geomatics Engineering, Calgary, AB, Canada, 2003.

82. Mendes, V. Modeling the Neutral Atmosphere Propagation Delay in Radiometric Space Techniques. Ph.D. Thesis, The University of New Brunswick, Fredericton, NB, Canada, 1998.

83. Nilsson, T.; Böhm, J.; Wijaya, D.D.; Tresch, A.; Nafisi, V.; Schuh, H. Path Delays in the Neutral Atmosphere. In Atmospheric Effects in Space Geodesy; Böhm, J., Schuh, H., Eds.; Springer: Berlin/Heidelberg, Germany, 2013; pp. 73-136. 
84. Hordyniec, P.; Kapłon, J.; Rohm, W.; Kryza, M. Residuals of Tropospheric Delays from GNSS Data and Ray-Tracing as a Potential Indicator of Rain and Clouds. Remote Sens. 2018, 10, 1917. [CrossRef]

85. Zus, F.; Douša, J.; Kačmařík, M.; Václavovic, P.; Dick, G.; Wickert, J. Estimating the Impact of Global Navigation Satellite System Horizontal Delay Gradients in Variational Data Assimilation. Remote Sens. 2018, 11, 41. [CrossRef] article distributed under the terms and conditions of the Creative Commons Attribution (CC BY) license (http://creativecommons.org/licenses/by/4.0/). 